\title{
Road transport: new life cycle inventories for fossil-fuelled passenger cars and non-exhaust emissions in ecoinvent $v 3$
}

\author{
Andrew Simons
}

Received: 14 December 2012 / Accepted: 7 August 2013 / Published online: 27 August 2013

(C) Springer-Verlag Berlin Heidelberg 2013

\begin{abstract}
Purpose The paper presents new and updated datasets for the operation of fossil-fuelled passenger cars. These are intended to be used either as background processes or in the comparative assessment of transport options. Central goals were to achieve a high level of consistency, transparency and flexibility for a representative range of current vehicle sizes, emission standards and fuel types, and to make a clear definition between exhaust and non-exhaust emissions. The latter is an important contribution to studies focusing on hybrid and electric vehicles.

Methods The datasets are the direct development of those available in ecoinvent v2 and are largely based on updated versions of the same sources. The datasets address petrol, diesel and natural gas vehicle fuels. The number of datasets was increased to cover small, medium and large vehicles. Other data sources were used in order to fill data gaps and to balance inconsistencies, particularly for the natural gas vehicles. Parameterisation was incorporated via the ecoeditor tool. This allows the datasets to be adapted for use as foreground processes and also increases transparency. An important method used was to observe the trends in fuel consumption and emissions across all sizes and emission standards simultaneously so that consistency would be achieved across the whole range of vehicles. Non-exhaust emissions were made dependent on vehicle weight and thereby independent of vehicle type.

Results and discussion Some significant changes in individual emission factors between the v2 and v3 datasets was shown. This can be explained by a combination of corrections, updates based on more recent versions of the data sources, and attempts to make the datasets consistent to each other. This has also meant that the non-exhaust emissions are readily
\end{abstract}

Responsible editor: Rainer Zah

A. Simons $(\bowtie)$

Laboratory for Energy Systems Analysis, Paul Scherrer Institute, 5232 Villigen PSI, Switzerland

e-mail: andrew.simons@psi.ch definable in terms of brake, tyre and road wear as a factor of vehicle weight, with the intention that this data can be applied to passenger vehicles of all technologies.

Conclusions Fuel consumption, emission factors and infrastructure demand have been improved, extended and updated for petrol, diesel and natural gas vehicles adhering to the Euro 3, 4 and 5 emissions standards. Using the ecoeditor tool, significant parameterisation was included which has made the datasets far more flexible, consistent and transparent. The clear definition of non-exhaust emissions means that these can easily be applied to studies on hybrid and electric vehicles.

Keywords Ecoinvent v3 $\cdot$ Emission factors $\cdot$ Emission standards · Life cycle assessment $\cdot$ Non-exhaust emissions . Passenger cars $\cdot$ Vehicle categories

\section{Introduction}

Due to a broad and intensifying range of issues such as fuel demand, fuel costs and fluctuation, energy security, greenhouse gas emissions, air pollution, transport planning etc., the focus of much ongoing research - LCA included - is the comparison of vehicle types and fuel chains; from fuel blends or alternative fuels (i.e. ethanol, biodiesel or synthetic natural gas) used in more or less "conventional" vehicles to radically different drivetrain concepts (i.e. all electric, hybrids, fuel cell hybrids, etc.). Of particular relevance to LCA is that alternatives to the currently dominating petrol and diesel vehicles should pose a transition to more efficient and less polluting mobility. Forming such comparisons depends heavily upon having suitable representations of the reference vehicle technologies ${ }^{1}$. Some important studies comparing alternative vehicle technologies and

\footnotetext{
${ }^{0}$ These reference technologies are here considered to be conventional passenger cars; meaning those using petrol, diesel or compressed natural gas fuelled internal combustion engines (ICE).
} 
therefore using the conventional as reference technology have been by (Schafer et al. 2006; Van Mierlo et al. 2006; Hussain et al. 2007; Samaras and Meisterling 2008; Huo et al. 2009; Notter et al. 2010; Hawkins et al. 2012). Establishing representative inventory data for such reference vehicles is made difficult because passenger cars fulfil a very high diversity of transport demands on a broad range of road types and according to different driving styles. In addition, and as previously described by Querini et al. (2011) in this journal, achieving an exact representation of each vehicle type is unrealistic because even conventional vehicles complying to the same emissions regulation standard can exhibit wide variation in their actual level of emissions. With regard to the ecoinvent database, datasets functioning as background vehicle use processes will therefore only be representative of very average conditions. If they are to be adapted for use as foreground processes, then the modelling of fuel consumption and emissions factors must be consistent and transparent, and the factors representing variables to the users must be clear to understand.

\subsection{Goal}

LCA has formed a key element of the THELMA ${ }^{2}$ project to assess and compare current and future scenarios for the transition to electric mobility in Switzerland. In order to do this, it was necessary to have up-to-date and representative inventories for a broad range of conventional fossil fuel internal combustion engine vehicles (ICEV). The PSI is a founding partner of the ecoinvent database and a main provider of the original transport datasets. Upon re-examination of the v2.0 data collection files, the methods and databases underlying the European (RER) vehicle operation inventories of ecoinvent v2.0 (Spielmann et al. 2007) were found to be outdated and partly incorrect methodologically. The previous datasets also only addressed a single vehicle size and did not expand on the broader range of vehicle categories and emission profiles provided by the data sources, therefore limiting the scope for users. It was therefore decided to update and improve the passenger car transport inventory datasets for the new version of the database (version v3) and to exploit the use of properties and parameters in order to improve transparency and to allow flexibility according to the needs of the user. Introducing flexibility means that the datasets can function both as background and foreground processes in an LCA. This paper describes the changes to the passenger car transport datasets, particularly the fuel consumption and emissions data contained within them. The most significant changes occurred on the side of the exhaust and non-exhaust emissions and so the paper will focus more heavily on these. The paper presents both new and updated versions of datasets for the operation of fossil-fuelled passenger cars. These are intended to

\footnotetext{
$\overline{2}$ TecHnology centered ELectric Mobility Assessment: www.http://www. thelma-emobility.net/
}

be used either as background processes or in the comparative assessment of transport options. Central goals were to achieve a high level of consistency, transparency and flexibility for a representative range of current vehicle sizes, emission standards and fuel types, and to make a clear definition between exhaust and non-exhaust emissions.

\section{Methods}

\subsection{Scope}

\subsubsection{New datasets}

Ecoinvent v2.2 contains 24 inventory datasets for passenger car transport with ICE technology. Of these, seven are specifically for unblended petrol vehicles, eight are for diesel vehicles, whilst just one dataset represents natural gas vehicles. Where not otherwise specified, the datasets are representative of medium size vehicles (1.4 to 2.0 1). The remaining ICE transport datasets are either for vehicles using biofuels or blends of petrol and biofuels, or they are non-specific in terms of fuel use and therefore refer to average transports in the two regions covered: Switzerland (CH) and Europe (RER). The new inventories for v3 and described in this paper replace some of the v2.2 datasets whilst simultaneously increasing the range of vehicles represented. Specific datasets meant to represent fleet average transports will no longer be needed in $\mathrm{v} 3$ due to the dynamic and automatic generation of market datasets. These reflect the contributions of the specific technologies according to their region-specific annual production volumes (APV), i.e. yearly travelled distances per vehicle technology. Table 1 shows the previously existing (v2.2) and new (v3) datasets.

As a transport fuel, $\mathrm{CNG}$ is seen as a cleaner burning fuel and is gaining in popularity but still does not yet have anything like the market shares which do petrol or diesel (Nijboer 2010). Although Euro standards for CNG vehicles have not yet been defined, the same data model used to define petrol and diesel fuel use and exhaust emissions for the v3 datasets (De Ceuster et al. 2007) also provides data for CNG vehicles and according to the same Euro standards.

For v3, the availability of data in (De Ceuster et al. 2007; Ntziachristos et al. 2009) allowed an expansion to differentiate between small ( $<1.41$ engine displacement), medium (1.4-2.0 1 engine displacement) and large $(<2.01$ engine displacement $)$ vehicles. This was done consistently for petrol, diesel and CNG fuelled vehicles and for the Euro 3, 4 and 5 emissions standards. Particularly for the $\mathrm{CNG}$ vehicles, additional data sources were needed in order to fill data gaps. Here, particularly the work of Alvarez and Weilenmann (2010) was used, as well as other natural gas combustion process in ecoinvent. Although Euro 3 now represents a relatively aged technology (cars sold in the years 2000 to 2004), these cars are still very much on the road, 
Table 1 ICE passenger car transport datasets existing within ecoinvent v2.2 and those replacing or additional in $\mathrm{v} 3$
In v3, the size categories "small" refers to vehicles with engine displacements of $<1.41$ and a reference mass of $1,200 \mathrm{~kg}$; "medium" is $1.4-2.01$ and $1,600 \mathrm{~kg}$; "large" is $>2.01$ and $2,000 \mathrm{~kg}$. Besides the European inventories ("RER"), also global (“GLO") transforming and market activities are generated due to the requirements of the database. The exchanges and values in these global datasets are currently the same as in the European datasets but with adjusted uncertainties

\begin{tabular}{|c|c|c|c|c|c|c|c|}
\hline \multicolumn{4}{|c|}{ v2.2 datasets } & \multicolumn{4}{|c|}{ Replaced by or additional in v3 } \\
\hline \multirow[t]{4}{*}{ Fuel } & \multirow[t]{4}{*}{ Technology } & & Region & Fuel & Size & Technology & Region \\
\hline & & & & Petrol & Small & Euro 3 & RER \\
\hline & & & & Petrol & Small & Euro 4 & RER \\
\hline & & & & Petrol & Small & Euro 5 & RER \\
\hline Petrol & Euro 3 & & $\mathrm{CH}$ & Petrol & Medium & Euro 3 & RER \\
\hline Petrol & Euro 4 & & $\mathrm{CH}$ & Petrol & Medium & Euro 4 & RER \\
\hline Petrol & Euro 5 & & $\mathrm{CH}$ & Petrol & Medium & Euro 5 & RER \\
\hline Petrol & Fleet av. & 2010 & $\mathrm{CH}$ & Removed & & & \\
\hline Petrol & Fleet av. & 2010 & RER & Removed & & & \\
\hline Petrol & Fleet av. & & $\mathrm{CH}$ & Removed & & & \\
\hline \multirow[t]{4}{*}{ Petrol } & Fleet av. & & RER & Removed & & & \\
\hline & & & & Petrol & Large & Euro 3 & RER \\
\hline & & & & Petrol & Large & Euro 4 & RER \\
\hline & & & & Petrol & Large & Euro 5 & RER \\
\hline \multirow[t]{4}{*}{ Diesel } & Euro 5 & City & $\mathrm{CH}$ & Removed & & & \\
\hline & & & & Diesel & Small & Euro 3 & RER \\
\hline & & & & Diesel & Small & Euro 4 & RER \\
\hline & & & & Diesel & Small & Euro 5 & RER \\
\hline Diesel & Euro 3 & & $\mathrm{CH}$ & Diesel & Medium & Euro 3 & RER \\
\hline Diesel & Euro 4 & & $\mathrm{CH}$ & Diesel & Medium & Euro 4 & RER \\
\hline Diesel & Euro 5 & & $\mathrm{CH}$ & Diesel & Medium & Euro 5 & RER \\
\hline Diesel & Fleet av. & 2010 & $\mathrm{CH}$ & Removed & & & \\
\hline Diesel & Fleet av. & 2010 & RER & Removed & & & \\
\hline Diesel & Fleet av. & & $\mathrm{CH}$ & Removed & & & \\
\hline \multirow[t]{4}{*}{ Diesel } & Fleet av. & & RER & Removed & & & \\
\hline & & & & Diesel & Large & Euro 3 & RER \\
\hline & & & & Diesel & Large & Euro 4 & RER \\
\hline & & & & Diesel & Large & Euro 5 & RER \\
\hline \multirow[t]{10}{*}{ Nat. gas } & & & $\mathrm{CH}$ & Removed & & & \\
\hline & & & & Nat. gas & Small & Euro 3 & RER \\
\hline & & & & Nat. gas & Small & Euro 4 & RER \\
\hline & & & & Nat. gas & Small & Euro 5 & RER \\
\hline & & & & Nat. gas & Medium & Euro 3 & RER \\
\hline & & & & Nat. gas & Medium & Euro 4 & RER \\
\hline & & & & Nat. gas & Medium & Euro 5 & RER \\
\hline & & & & Nat. gas & Large & Euro 3 & RER \\
\hline & & & & Nat. gas & Large & Euro 4 & RER \\
\hline & & & & Nat. gas & Large & Euro 5 & RER \\
\hline
\end{tabular}

and therefore, require relevant LCA data. Additionally, a main aim of the improvements to the datasets was also to introduce consistent trends in the data across Euro standards as well as across vehicle sizes. Trend analysis also acts as a control mechanism for the inventory data of the more recent technologies.

\subsubsection{Dataset structure}

The differences in the basic structure of the transport datasets can be seen in Fig. 1a, b. In ecoinvent v2 datasets, the fuel consumption (FC) and direct emissions from vehicle operation were all contained within a passenger car operation dataset which formed a unified input to the transport dataset. On the inventory level, this meant that it was difficult to distinguish between exhaust and non-exhaust emissions and therefore did not enable a high level of transparency. On the impact assessment level it meant that additional efforts were needed to follow the process chains in order to differentiate the burdens caused by FC and the various direct emissions sources. In v3, transport inputs and emissions are grouped 
Fig. 1 a The basic structure of the passenger car transport datasets used in ecoinvent $\mathrm{v} 2$. $\mathbf{b}$ The basic structure of the passenger car transport datasets introduced in ecoinvent $\mathrm{v} 3$ a

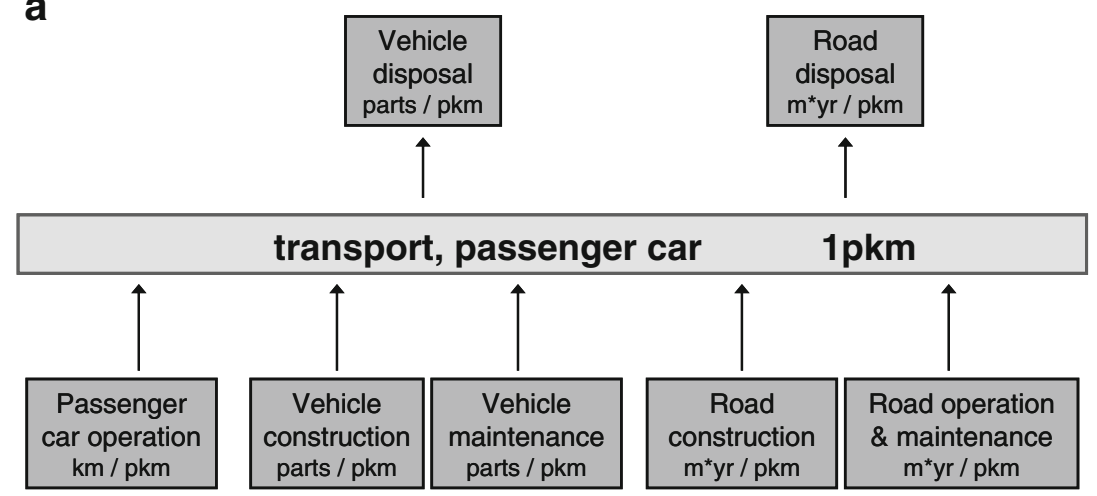

b

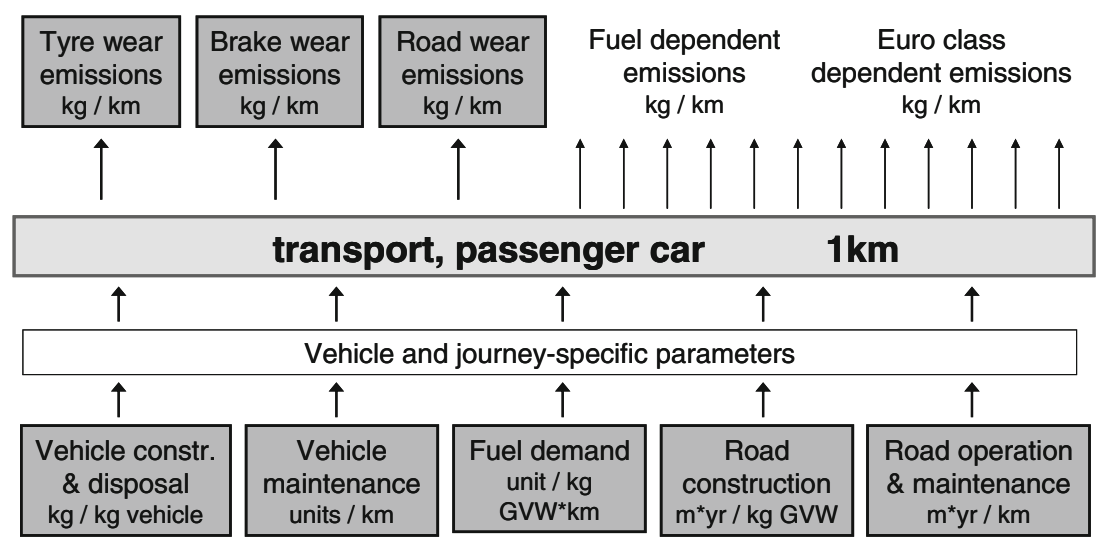

according to their source and dependency, and vehicle operation as an intermediate process has been eliminated. With the variation in vehicle sizes, it has been possible to make the demand for all suitable exchanges relevant to the gross vehicle weight (GVW) which is the vehicle plus load or passengers. This is of particular relevance for FC. In terms of emissions, a clear separation is made between exhaust and non-exhaust emissions with further differentiation between those which are fuel dependent and those which are regulated, i.e. Euro class dependent. Non-exhaust emissions are differentiated between brake, tyre, road surface abrasion or fuel evaporation ${ }^{3}$. Such modularisation was done in order to allow greater transparency and flexibility, and to enable LCA comparisons of vehicles using ICE and those using alternative drivetrains, i.e. hybrid, all electric or fuel cell vehicles (for which non-exhaust emissions are the only direct emissions during driving and for

\footnotetext{
${ }^{3}$ Fuel evaporation emissions are given for petrol cars only and are included as individual exchanges along with the fuel dependent emissions. According to the EMEP/EEA (Ntziachristos et al. 2009), evaporative emissions from diesel vehicles are negligible and can be neglected in calculations. This is due to the presence of heavier hydrocarbons and the relatively low vapour pressure of diesel fuel. A quantification of VOC emissions from natural gas vehicles is not given.
}

which the brake wear emissions may be reduced due to recuperative braking over the electric motor). The data sources also allowed a significant expansion of the non-exhaust emissions profiles. The non-exhaust emissions from the abrasion of brakes, tyres and road surface are now accounted for as treatment datasets, in effect therefore accounting for the emissions as a removal of material from the technosphere.

The data for vehicle and road infrastructures is the same as in $\mathrm{v} 2$, but the inventories were redefined in order to distinguish between technology-relevant aspects such as vehicle glider and drivetrain (see the paper by Del Duce et al. 2013), and to merge processes of less significance such as road construction and disposal.

\subsubsection{Parameters}

One of the most significant changes included in $\mathrm{v} 3$ is the use of parameters. In the transport datasets, these have the aim of increasing transparency and flexibility. From a dataset development perspective, they are used to define and extrapolate vehicle characteristics, to provide an intermediary calculation and conversion platform and to allow live-linked data to be used in the mathematical relations of the exchanges. For use as foreground datasets, it is possible for users to change the 


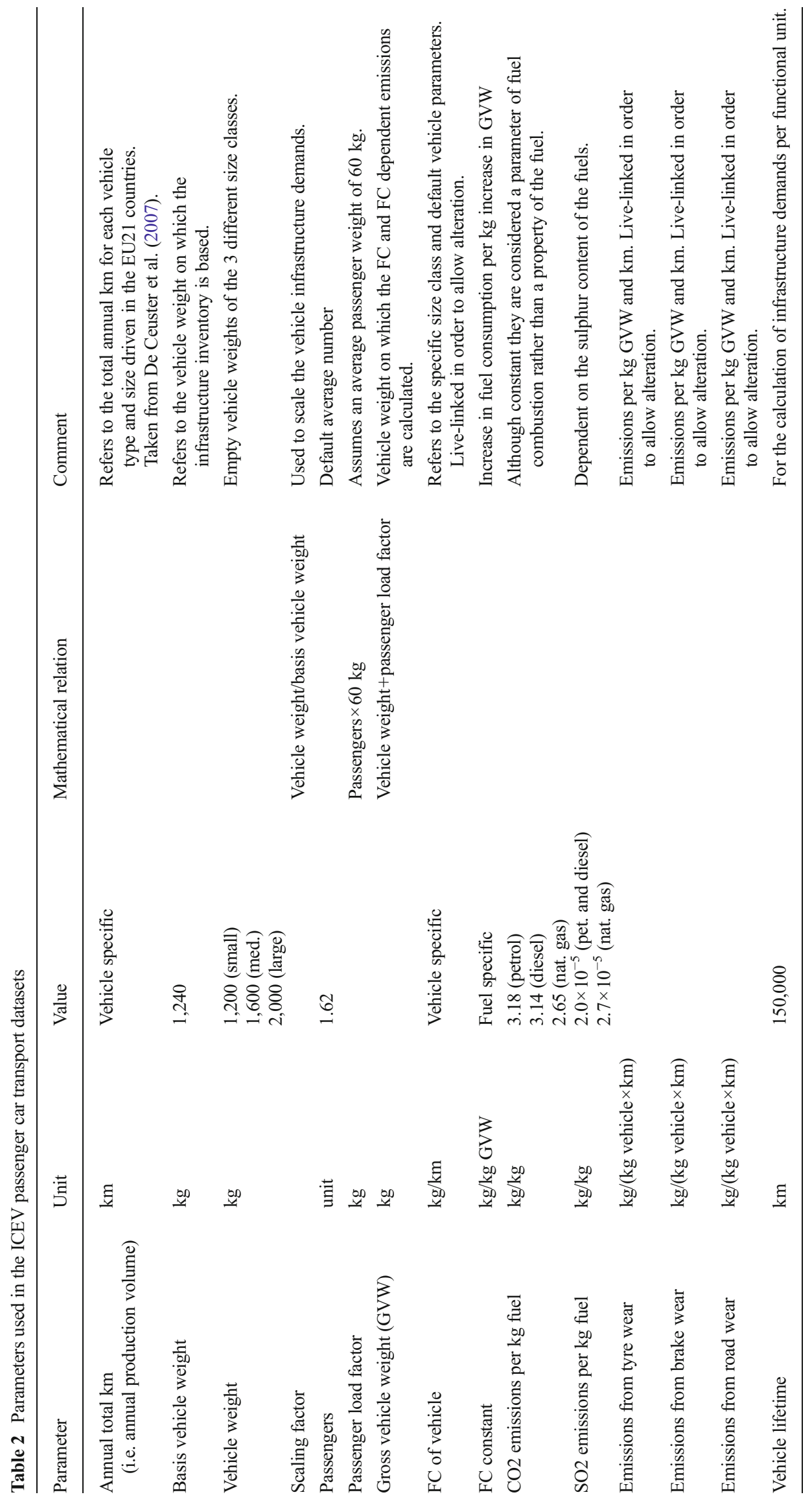


specific parameters relating to number of passengers and FC. Changing these then automatically alters GVW (and thereby also non-exhaust emissions and road infrastructure demand) and fuel dependent emissions. Table 2 provides an overview of the parameters, with further definition available when the datasets are opened using the ecoeditor tool.

\subsection{Functional unit}

The functional unit (FU) of the transport datasets described here is $1 \mathrm{~km}$ of passenger car transport according to the GVW and in the default settings is representative of average ${ }^{4}$ driving conditions (i.e. not according to a specific driving cycle). The use of $1 \mathrm{~km}$ replaces the FU of 1 passenger kilometer $(1 \mathrm{pkm})$ used in $\mathrm{v} 2$.

\subsection{Data collection}

The work on updating the inventories for ecoinvent $\mathrm{v} 3$ strived to generate consistent trends across vehicles using the same fuel, meaning simply a regular increase in FC and emissions between vehicle sizes as well as consistent differences of the Euro classes. In terms of consistency between the fuels, as much as possible, the compilation of inventory data used the same methodology and data sources. The transport service provided by the different fuels is therefore assumed to be equal.

Exhaust emissions data taken from the TREMOVE model (De Ceuster et al. 2007) used the v2.7b code and the reference year 2010. Here data were used from an EU-21 list of countries $^{5}$ and, in reference to the road types, used all regions and all road networks in order to be relevant to average driving conditions. This means that a further possible advancement of the datasets in the future would be to define FC and emissions profiles for different road types, which would allow dataset users to specify fractions of highway or urban driving contributing to the functional unit. Data for additional exhaust emissions not found in the TREMOVE model was taken from (Ntziachristos et al. 2009). Non-exhaust emissions data (including petrol evaporation) was taken from (Mellios et al. 2009; Ntziachristos and Boulter 2009). Due to unreliable data or data gaps for natural gas consumption and exhaust emissions in both (De Ceuster et al. 2007) and (Ntziachristos et al. 2009), the findings of Alvarez and Weilenmann (2010) were extrapolated where necessary.

\footnotetext{
${ }^{4}$ In this context the word "average" refers to the fuel consumption, the relationship between fuel consumption and fuel-dependent emissions, and the relationship between vehicle size and Euro-class dependent emissions based on the data sources as described in the text and representing the European vehicle fleet on the road in 2010.

${ }^{5}$ AT, BE, CH, CZ, DE, DK, ES, FI, FR, GR, HU, IE, IT, LU, NL, NO, PT, PU, SE, SI and UK
}

\subsubsection{Fuel consumption}

Values for petrol and diesel consumption were taken directly from the TREMOVE model v2.7b (De Ceuster et al. 2007). The FC and emission factors represent real world conditions and tend to be on the order of $20 \%$ higher than those reported for the new European driving cycle (NEDC). A significant contribution to this increase is due to the more dynamic driving behaviour in real life as opposed to the NEDC as well as fuel consumption for driver auxiliaries, i.e. lights, wipers, electronics and, more recently, also air conditioning. The relationships between $\mathrm{FC}$ and $\mathrm{CO}_{2}$ emissions were found to be consistent with values given in (Ntziachristos et al. 2009), i.e. $3.18 \mathrm{~kg} \mathrm{CO}_{2} / \mathrm{kg}$ petrol and $3.14 \mathrm{~kg} \mathrm{CO}_{2} / \mathrm{kg}$ diesel.

For CNG, the values from TREMOVE were found to be inconsistent with the $\mathrm{CO}_{2}$ emissions which, according to the composition of natural gas in ecoinvent (Faist Emmenegger et al. 2007) as well as other CNG combustions provided in ecoinvent (such as natural gas fuelled combined heat and power (Heck 2007) or combined cycle power plants (Faist Emmenegger et al. 2007), must be around $2.65 \mathrm{~kg} \mathrm{CO}_{2}$ per kg natural gas. $\mathrm{FC}$ was then calculated from the $\mathrm{CO}_{2}, \mathrm{CO}$ and VOC (termed hydrocarbons $[\mathrm{HC}]$ in the Euro standards) emissions using the following equation (taken from Alvarez and Weilenmann 2010), which accounts for CNG and VOCs (HC) as methane $\left(\mathrm{CH}_{4}\right)$ :

Mass $C N G=16^{*}\left(\right.$ MassCO $_{2} / 44+$ Mass CO28 + Mass $\left.H C / 16\right)$

\subsubsection{Exhaust emissions}

For the purposes of data processing, the exhaust emissions were grouped under categories similar to those used in ecoinvent v2 (Spielmann et al. 2007). These do not necessarily follow the grouping used by the EMEP/EEA (Ntziachristos et al. 2009):

- Group 1: Airborne exhaust emissions dependent on FC and fuel composition (quality).

- Group 2: Airborne exhaust pollutants dependent on regulated limits according to the Euro norm standards (Directives 98/69/EC and 715/2007/EC). These include total hydrocarbons (HC).

- Group 3: Specific hydrocarbon profiles (HC split).

European directive 2009/30/EC on the specification of petrol and diesel fuels for road transport defines a limit of $10 \mathrm{mg}$ sulphur $/ \mathrm{kg}_{\text {fuel }}$. Assuming that all sulphur is converted to sulphur dioxide $\left(\mathrm{SO}_{2}\right)$ and exhausted from the vehicle in full then the resulting emissions equate to $20 \mathrm{mg} \mathrm{so} 2 / \mathrm{kg}$ fuel. This value was used for all petrol and diesel vehicles. For natural gas $(\mathrm{NG})$, the value of $0.55 \mathrm{mg} \mathrm{sO2} / \mathrm{MJ}_{\mathrm{NG}}$ or $26.4 \mathrm{mg} \mathrm{sO} 2 / \mathrm{kg} \mathrm{NG}$ was taken from existing ecoinvent 
Table 3 Exhaust emissions (condensed) and their data sources for the different fossil fuels

\begin{tabular}{|c|c|c|c|c|}
\hline Emision group & Emission & Data source & Data source & Data source $\mathrm{CNG}$ \\
\hline \multirow[t]{6}{*}{ Gr 1} & Carbon dioxide $\left(\mathrm{CO}_{2}\right)$ & 1 & 1 & Extrapolations of 3 \\
\hline & Sulphur dioxide $\left(\mathrm{SO}_{2}\right)$ & 1 & 1 & 1 \\
\hline & Heavy metals ${ }^{*}$ & 2 & 2 & 4 \\
\hline & Dinitrogen monoxide $\left(\mathrm{NO}_{2}\right)$ & 2 & 2 & 1 \\
\hline & Ammonia $\left(\mathrm{NH}_{3}\right)$ & 2 & 2 & Extrapolations of 3 \\
\hline & Poly aromatic hydrocarbons (PAH) & 2 & 2 & Not present \\
\hline \multirow[t]{3}{*}{ Gr 2} & Carbon Monoxide (CO) & 1 & 1 & Extrapolations of 3 \\
\hline & Nitrogen Oxides $\left(\mathrm{NO}_{\mathrm{x}}\right)$ & 1 & 1 & 1 \\
\hline & Particulate Matter $\left(\mathrm{PM}_{2.5}\right)$ & 1 & 1 & 1 \\
\hline \multirow[t]{3}{*}{ Gr3 } & Methane $\left(\mathrm{CH}_{4}\right)$ & 1 & 1 & Extrapolations of 3 \\
\hline & Total non-methane volatile organic compounds (NMVOC) & 1 & 1 & Extrapolations of 3 \\
\hline & (NMVOC) split & 2 & 2 & Extrapolations of 3 \\
\hline
\end{tabular}

* The term "heavy metals" is used in this paper as a general term to cover those metals and semimetals posing a potential human or environmental toxicity at low concentrations

1 TREMOVE model code v2.7b (De Ceuster et al. 2007)

2 EMEP/EEA Emissions Inventory Guidebook (Ntziachristos et al. 2009)

3 (Alvarez and Weilenmann 2010) and extrapolated to cover all vehicle classes, using the equivalent relationships for petrol vehicles

4 Ecoinvent report: Erdgas (Faist Emmenegger et al. 2007)

processes for natural gas combusted in ICE combined heat and power plants.

In the accounting of regulated emissions (group 2), it is clearly important that values in the inventories do not exceed the limits stipulated. The analysis of these is given below. The Euro standards for petrol emissions were applied to $\mathrm{CNG}$ because both use a spark ignition engine (as opposed to compression ignition). Due to the relatively very low number of vehicles determined in the TREMOVE model the data is however partly inconsistent and unacceptable. Data from (Alvarez and Weilenmann 2010) was therefore used in order to form appropriate emission factors.

In the transport datasets, group 3 is the finer resolution of the HC Euro-regulated pollutant. Table 3 summarises the new emission profiles and sources of inventory data used in this paper.

In many regards, the TREMOVE model and EMEP/EEA guidebook are interrelated because the former is based heavily on the latter. The TREMOVE model was used because it provides a comprehensive interpretation of the EMEP/EEA guidebook (Ntziachristos et al. 2009) for fuel consumption and key emission factors, as well as total European fleet data for use in annual production volumes and road infrastructure allocation. The EMEP/EEA guidebook (Ntziachristos et al. 2009; Ntziachristos and Boulter 2009) was then referred to directly in cases of inconsistency and for the broader range of emissions not accounted for in the TREMOVE model, i.e. NMVOC splits and non-exhaust emissions.

$\mathrm{CO}_{2}$ emissions from passenger cars have not been directly regulated under the Euro standards but, as of 2012, vehicles will have to conform to increasingly more stringent $\mathrm{CO}_{2}$ emissions regulations according to Directive 443/2009/EC. The regulations are in order to achieve the European Commission's 2020 target for average emissions from new cars of $95 \mathrm{~g} \mathrm{CO}_{2} / \mathrm{km}$ with a mandatory target of $130 \mathrm{~g}$ for 2015. In 2011, the average was 135.7 g. Here "average" refers to the average of all vehicles sold within a specific period. Vehicle specific emissions for the period 2012 to 2015 (new vehicles sold within this period) are calculated according to the following equation, based on vehicle operation over the New European Driving Cycle (NEDC):

$\mathrm{CO}_{2}=130+0.0457 \times\left(\mathrm{M}-\mathrm{M}_{0}\right)$

\section{Where}

M mass of the vehicle in $\mathrm{kg}$

$\mathrm{M}_{0}$ the average mass of new passenger cars in $\mathrm{kg}$, currently represented by the value of 1372

Applying (1) to the different vehicle sizes and weights used in the present paper gives $\mathrm{CO}_{2}$ emission limits of 122,140 and $159 \mathrm{~g} / \mathrm{km}$ for small $(1,200 \mathrm{~kg})$, medium $(1,600 \mathrm{~kg})$ and large

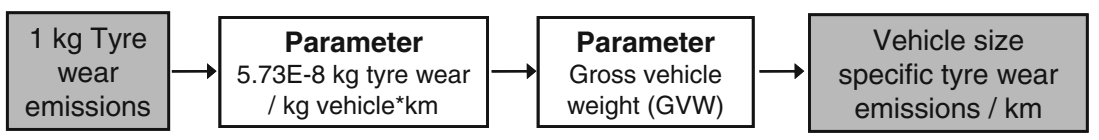

Fig. 2 Procedure for determining vehicle size specific non-exhaust emissions showing the example of tyre wear emissions 
Fig. 3 Default fuel consumption values for petrol, diesel and natural gas passenger cars using the masses of the basis vehicles, i.e. $1,200 \mathrm{~kg}$ for small, $1,600 \mathrm{~kg}$ for medium and 2,000 $\mathrm{kg}$ for large plus the mass of passengers (60 kg per passenger and 1.62 passengers per car which are values taken directly from v2)

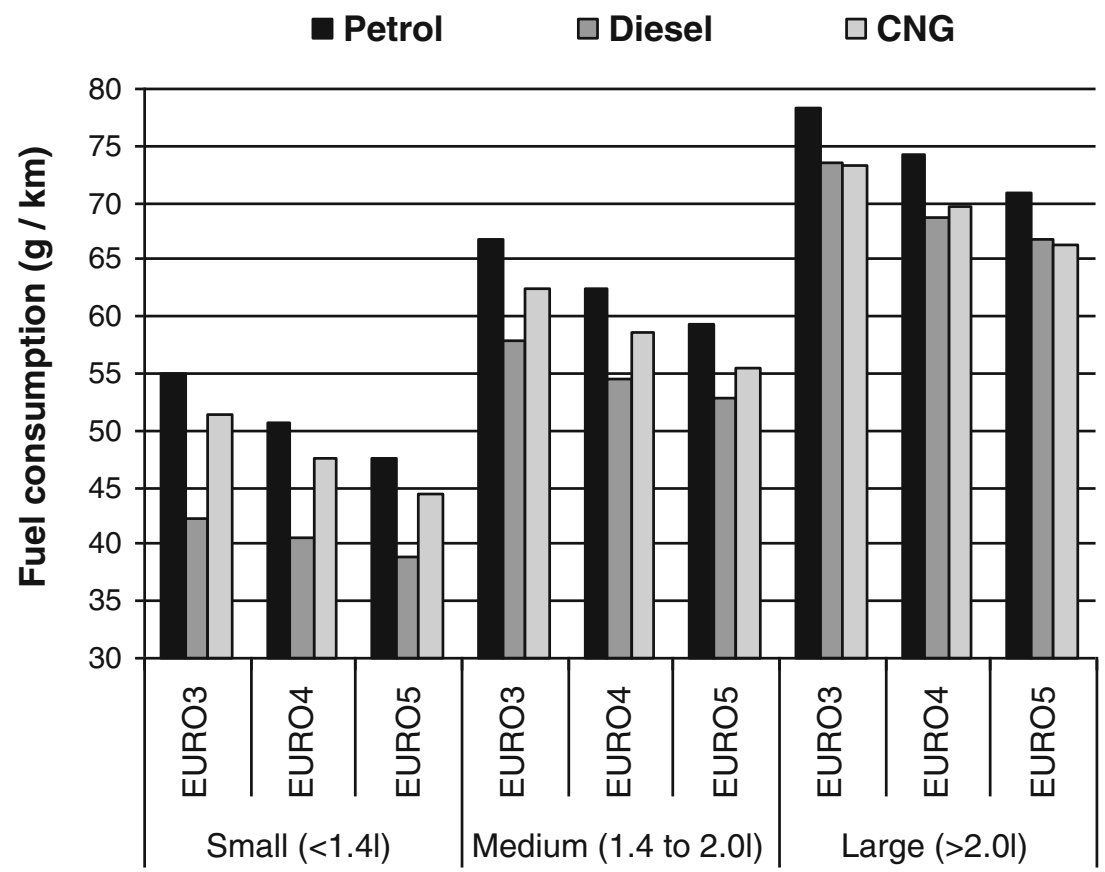

$(2,000 \mathrm{~kg})$ cars, respectively, and relevant to those of Euro 5 standard only (2009 to 2014). The emission factors presented in this paper are somewhat higher than these limits, firstly, because they are representative of vehicles in 2010, and secondly, because they are representative of average driving in Europe rather than being based on an analytical test cycle.

For petrol vehicles the emissions also include VOCs as a result of fuel evaporation. Here the total per $\mathrm{km}$ of vehicle use was taken from (Keller et al. 2004) with the specific VOC split taken from (Ntziachristos and Boulter 2009). Evaporation emissions are merged into the petrol exhaust emissions.

\subsubsection{Non-exhaust emissions}

Non-exhaust emissions consist of particulate matter (PM) from tyre and brake wear as well as from the abrasion of the road surface. They can be significant to an impact assessment because the PM emissions from tyres and brakes largely consist of metals, including significant proportions of heavy metals. Emissions to air are quantified in terms of PM size and the substance forming the PM. The size categories are those less than $2.5 \mu \mathrm{m}$, those between 2.5 and $10 \mu \mathrm{m}$ and those larger than $10 \mu \mathrm{m}$. Defining both a particles' size and of which specific substance, it is composed is important because the
Fig. 4 Regulated emissions from petrol cars according to the Euro norm standards

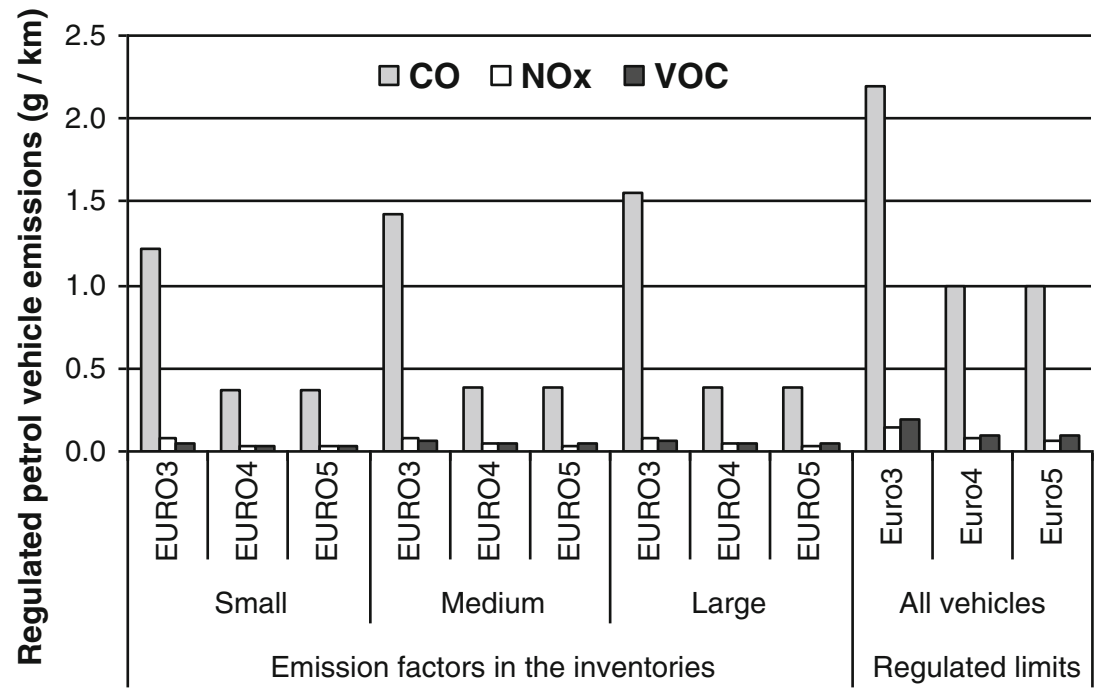


Fig. 5 Regulated emissions from diesel cars according to the Euro norm standards. PM exhaust emissions are accounted for as $\mathrm{PM}_{2.5}$

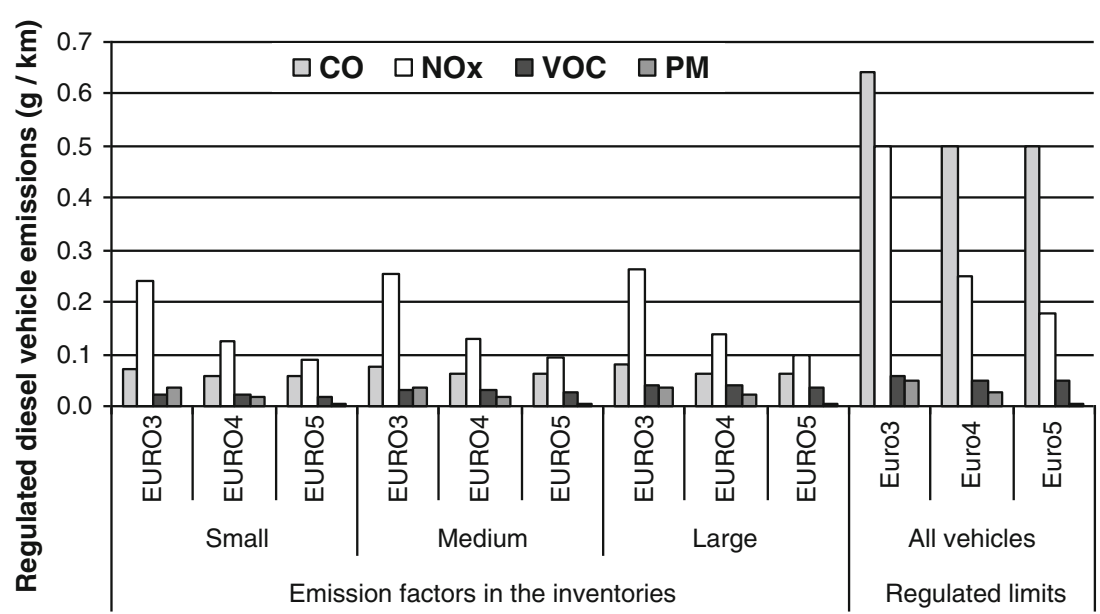

effects accounted for in impact assessment methodologies. This form of accounting is in conformity with the quality guidelines (Weidema et al. 2012). Based on (Ntziachristos and Boulter 2009), non-exhaust emissions to soil and water, i.e. directly received by the ground and water flows, are also determined for tyre wear. Changes to the non-exhaust emissions compared to ecoinvent $\mathrm{v} 2$ inventories were made due to a more recent version of the EMEP/EEA guidebook (Ntziachristos and Boulter 2009) and due to a previously partially incorrect interpretation of the PM mass fractions. The emissions profile was significantly expanded to include all the substances listed in the source data (certain substances were not previously listed in ecoinvent). Emission factors for small and large passenger vehicles were calculated by using the lower and higher bounds of the ranges given for the brake and tyre wear PM emissions of average vehicles. In order to maintain representativeness to specific vehicle size, the PM splits were extrapolated assuming that the values given represent medium size cars. For road abrasion emissions
(Ntziachristos and Boulter 2009), do not differentiate between vehicle sizes and also do not provide a profile of the substances released - the emissions are simply listed as PM. The abrasion emissions are shown in terms of mass per $\mathrm{km}$ and with reference to the GVW. Non-exhaust emissions per $\mathrm{km}$ could thus be scaled directly to vehicle weight, meaning that the emissions had to be defined in terms of $\mathrm{kg} / \mathrm{kg}$ vehicle and for $1 \mathrm{~km}(\mathrm{~kg} /(\mathrm{kg} \times \mathrm{km}))$. In order to facilitate this, quantities of individual emissions were quantified relevant to $1 \mathrm{~kg}$ of either tyre, brake or road wear. The calculation procedure with use of parameters is summarised in Fig. 2.

\subsubsection{Infrastructures}

The contributions from vehicle and road infrastructures were redefined in order to give a more useful oversight and greater flexibility. For a more detailed description of vehicle infrastructures, the reader is encouraged to refer to the paper by Del
Fig. 6 Emissions from $\mathrm{CNG}$ cars, determined according to the regulated emissions limits of the Euro norm standards for petrol cars

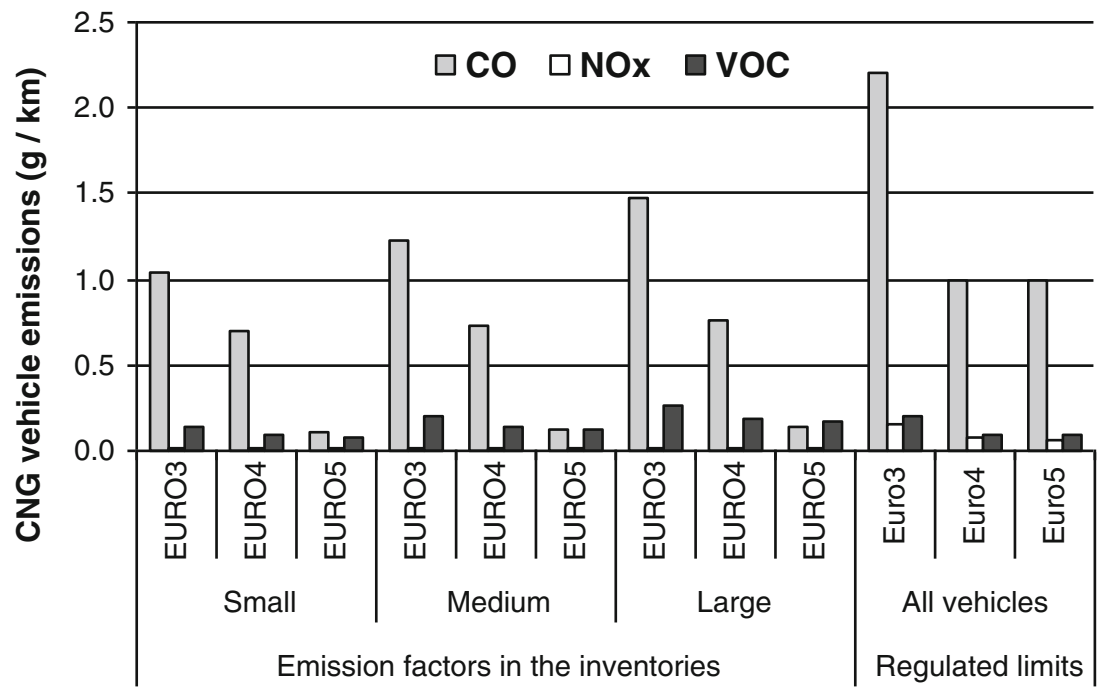


Table 4 Fuel consumption and exhaust emissions in kg per km passenger car transport. The table shows medium size cars only and is relevant for the basis vehicle weight in this size class i.e. $1600 \mathrm{~kg}$

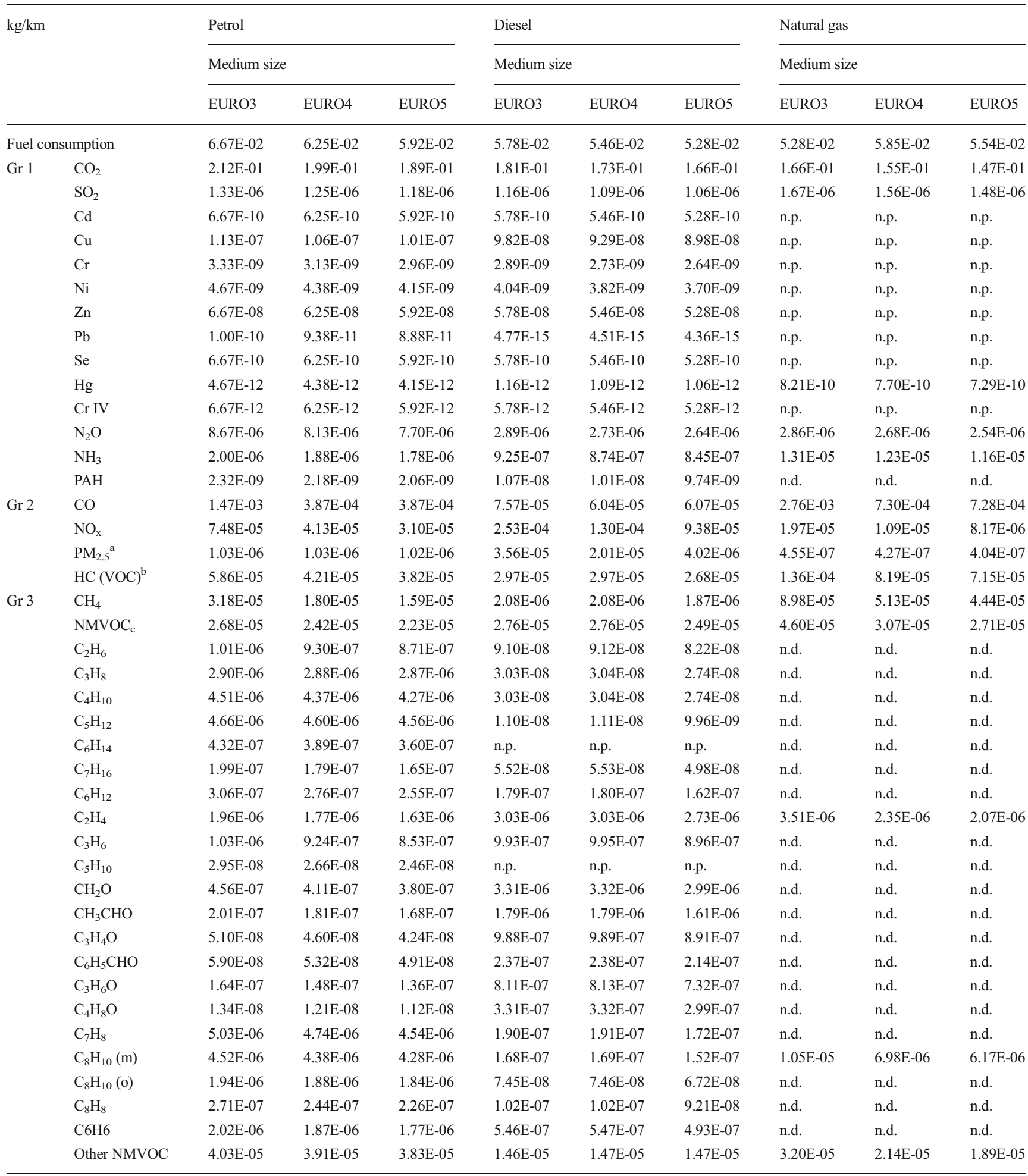

${ }^{\text {a }}$ Particulate matter (PM) is a regulated emission for diesel cars only. All PM are assumed to be less than 2.5 micro meters ( $\left.\mu \mathrm{m}\right)$ in diameter

${ }^{\mathrm{b}}$ Hydrocarbon (HC, or VOC in ecoinvent) emissions as a cumulative total are regulated under the Euro norm standards. The ecoinvent transport datasets use the total VOC in order to define the VOC split (group 3) and are therefore shown here for the purposes of calculation and completeness

'Total NMVOC's are shown for calculation purposes only, being the product of total $\mathrm{HC}$ minus $\mathrm{CH}_{4}$

n.p. Not present

n.d. No data available 
Fig. 7 Non-exhaust particulate matter (PM) emissions from passenger cars (Ntziachristos and Boulter 2009)

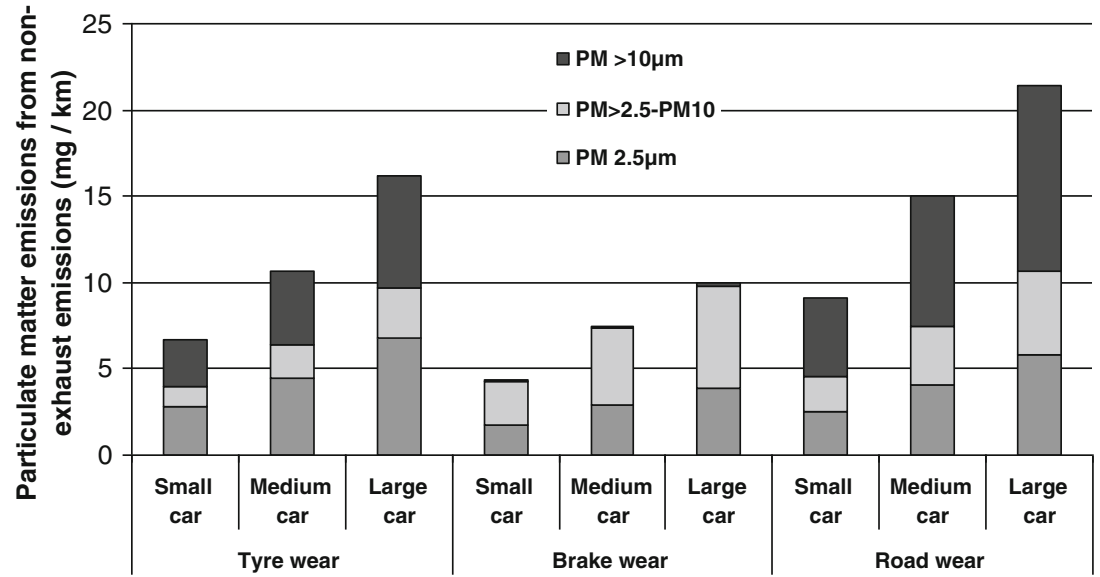

Table 5 Non-exhaust emission factors per $\mathrm{kg}$ tyre, brake or road abrasion, as well as $\mathrm{kg}$ abrasion per $\mathrm{kg}$ vehicle and $\mathrm{km}$

\begin{tabular}{|c|c|c|c|c|}
\hline \multirow{2}{*}{$\begin{array}{l}\text { Emissions source } \\
\text { Location of burden } \\
\text { Emission ( } \mathrm{kg} / \mathrm{kg} \text { total emissions) }\end{array}$} & \multicolumn{2}{|l|}{ Tyres } & \multirow{2}{*}{$\begin{array}{l}\text { Brakes } \\
\text { Air }\end{array}$} & \multirow{2}{*}{$\begin{array}{l}\text { Road } \\
\text { Air }\end{array}$} \\
\hline & Air & $\begin{array}{l}\text { Soil \& Water } \\
\text { (50/50 split) }\end{array}$ & & \\
\hline Particulates, $>10$ um & 4.74E-02 & & $2.00 \mathrm{E}-02$ & $5.00 \mathrm{E}-01$ \\
\hline Particulates, $>2.5 \mathrm{um}$, and $<10 \mathrm{um}$ & $2.14 \mathrm{E}-02$ & & $5.00 \mathrm{E}-01$ & $2.30 \mathrm{E}-01$ \\
\hline Particulates, $<2.5$ um & $4.98 \mathrm{E}-02$ & & $3.90 \mathrm{E}-01$ & $2.70 \mathrm{E}-01$ \\
\hline Total PM (equals total emissions to air) & 4.98E-02 & & $1.00 \mathrm{E}+00$ & $1.00 \mathrm{E}+00$ \\
\hline PAH, polycyclic aromatic hydrocarbons & $8.67 \mathrm{E}-07$ & & $2.47 \mathrm{E}-06$ & \\
\hline Silver & $2.22 \mathrm{E}-08$ & $1.65 \mathrm{E}-07$ & $0.00 \mathrm{E}+00$ & \\
\hline Aluminium & $7.20 \mathrm{E}-05$ & $5.36 \mathrm{E}-04$ & $2.85 \mathrm{E}-03$ & \\
\hline Arsenic & $8.44 \mathrm{E}-07$ & $6.28 \mathrm{E}-06$ & $9.38 \mathrm{E}-05$ & \\
\hline Barium & $2.78 \mathrm{E}-05$ & $2.07 \mathrm{E}-04$ & $5.35 \mathrm{E}-02$ & \\
\hline Bromine & 4.44E-06 & $3.31 \mathrm{E}-05$ & $5.56 \mathrm{E}-05$ & \\
\hline Calcium & $1.98 \mathrm{E}-04$ & $1.47 \mathrm{E}-03$ & $1.07 \mathrm{E}-02$ & \\
\hline Cadmium & $1.04 \mathrm{E}-06$ & 7.77E-06 & $3.11 \mathrm{E}-05$ & \\
\hline Chlorine & $1.16 \mathrm{E}-04$ & $8.60 \mathrm{E}-04$ & $2.08 \mathrm{E}-03$ & \\
\hline Cobalt & $2.84 \mathrm{E}-06$ & $2.12 \mathrm{E}-05$ & $8.89 \mathrm{E}-06$ & \\
\hline Chromium & $5.29 \mathrm{E}-06$ & $3.94 \mathrm{E}-05$ & $8.89 \mathrm{E}-06$ & \\
\hline Copper & $3.87 \mathrm{E}-05$ & $2.88 \mathrm{E}-04$ & $7.10 \mathrm{E}-02$ & \\
\hline Elemental carbon & $3.40 \mathrm{E}-02$ & $2.53 \mathrm{E}-01$ & $3.63 \mathrm{E}-02$ & \\
\hline Iron & $3.80 \mathrm{E}-04$ & $2.83 \mathrm{E}-03$ & $2.91 \mathrm{E}-01$ & \\
\hline Potassium & $6.22 \mathrm{E}-05$ & 4.63E-04 & 7.27E-04 & \\
\hline Lithium & 7.27E-04 & $2.15 \mathrm{E}-06$ & $7.72 \mathrm{E}-05$ & \\
\hline Manganese & $1.13 \mathrm{E}-05$ & $8.43 \mathrm{E}-05$ & $3.42 \mathrm{E}-03$ & \\
\hline Molybdenum & $6.22 \mathrm{E}-07$ & 4.63E-06 & $1.39 \mathrm{E}-02$ & \\
\hline Sodium & $1.43 \mathrm{E}-04$ & $1.07 \mathrm{E}-03$ & $1.08 \mathrm{E}-02$ & \\
\hline Nickel & $6.64 \mathrm{E}-06$ & 4.94E-05 & $4.54 \mathrm{E}-04$ & \\
\hline Nitrate & $3.33 \mathrm{E}-04$ & $2.48 \mathrm{E}-03$ & $2.22 \mathrm{E}-03$ & \\
\hline Organic carbon & $8.00 \mathrm{E}-02$ & $5.95 \mathrm{E}-01$ & $1.49 \mathrm{E}-01$ & \\
\hline Lead & $3.91 \mathrm{E}-05$ & 2.91E-04 & $8.43 \mathrm{E}-03$ & \\
\hline Sulfur as sulphur dioxide & 4.89E-04 & $2.30 \mathrm{E}-03$ & $3.56 \mathrm{E}-02$ & \\
\hline Antimony & 4.44E-07 & $3.31 \mathrm{E}-06$ & $1.39 \mathrm{E}-01$ & \\
\hline Selenium & 4.44E-06 & $3.31 \mathrm{E}-05$ & $2.78 \mathrm{E}-05$ & \\
\hline Silicon & $3.80 \mathrm{E}-04$ & $2.98 \mathrm{E}-03$ & $9.43 \mathrm{E}-02$ & \\
\hline
\end{tabular}


Table 5 (continued)

\begin{tabular}{|c|c|c|c|c|}
\hline \multirow{2}{*}{$\begin{array}{l}\text { Emissions source } \\
\text { Location of burden } \\
\text { Emission ( } \mathrm{kg} / \mathrm{kg} \text { total emissions) }\end{array}$} & \multicolumn{2}{|l|}{ Tyres } & \multirow{2}{*}{$\begin{array}{l}\text { Brakes } \\
\text { Air }\end{array}$} & \multirow{2}{*}{$\begin{array}{l}\text { Road } \\
\text { Air }\end{array}$} \\
\hline & Air & $\begin{array}{l}\text { Soil \& Water } \\
\text { (50/50 split) }\end{array}$ & & \\
\hline Sulfate & $5.55 \mathrm{E}-04$ & 4.13E-03 & 4.64E-02 & \\
\hline Tin & $0.00 \mathrm{E}+00$ & $0.00 \mathrm{E}+00$ & $9.72 \mathrm{E}-03$ & \\
\hline Strontium & $3.20 \mathrm{E}-06$ & $2.38 \mathrm{E}-05$ & $7.22 \mathrm{E}-04$ & \\
\hline Titanium & $8.40 \mathrm{E}-05$ & $6.25 \mathrm{E}-04$ & $5.00 \mathrm{E}-03$ & \\
\hline Vanadium & $2.22 \mathrm{E}-07$ & $1.65 \mathrm{E}-06$ & $9.17 \mathrm{E}-04$ & \\
\hline Zinc & $1.65 \mathrm{E}-03$ & $1.23 \mathrm{E}-02$ & $1.21 \mathrm{E}-02$ & \\
\hline Total & $1.19 \mathrm{E}-01$ & $8.81 \mathrm{E}-01$ & & \\
\hline Total & $1.00 \mathrm{E}+00$ & & $1.00 \mathrm{E}+00$ & $1.00 \mathrm{E}+00$ \\
\hline Abrasion $(\mathrm{kg} / \mathrm{kg}$ vehicle*km) & $5.73 \mathrm{E}-08$ & & 4.45E-09 & $9.79 \mathrm{E}-09$ \\
\hline
\end{tabular}

Duce et al. (2013) also published in this special issue. The data upon which the inventories for road infrastructures are based has not been updated.

Vehicles The new transport datasets scale the vehicle infrastructure based on the difference between the weight of the vehicle upon which the construction inventory is based $(1,240 \mathrm{~kg})$ and that of the vehicle fulfilling the specific transport service. Vehicle maintenance is accounted for as a separate process.

Road The demand for road infrastructures is still differentiated between construction and disposal (provision) and operation and maintenance. Road provision is now parameterised according to GVW, whilst the operation and maintenance (electricity for lighting, line painting and de-weeding) retains an equal allocation according to $\mathrm{km}$ transport.

\section{Results}

\subsection{Version 3 inventory data}

FC for all vehicles are given in Fig. 3. Due to the similarity in the combustion technologies, petrol and natural gas consumption maintains a consistent difference across all vehicle sizes and Euro classes. For diesel, however, the difference to the other two fuels is seen to diminish with increasing vehicle size. The FC of petrol and diesel vehicles was taken with only
Fig. 8 Comparison of petrol vehicle operation inventory data and using Euro 5 as an example

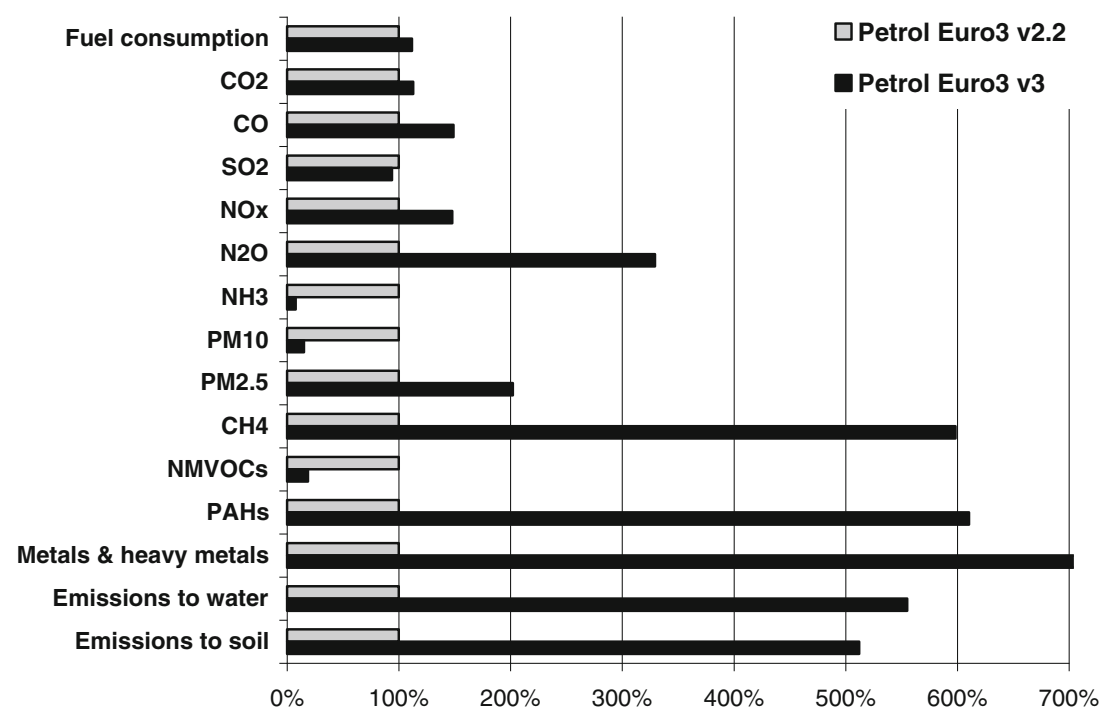


Fig. 9 Comparison of diesel vehicle operation inventory data and using Euro 5 as an example

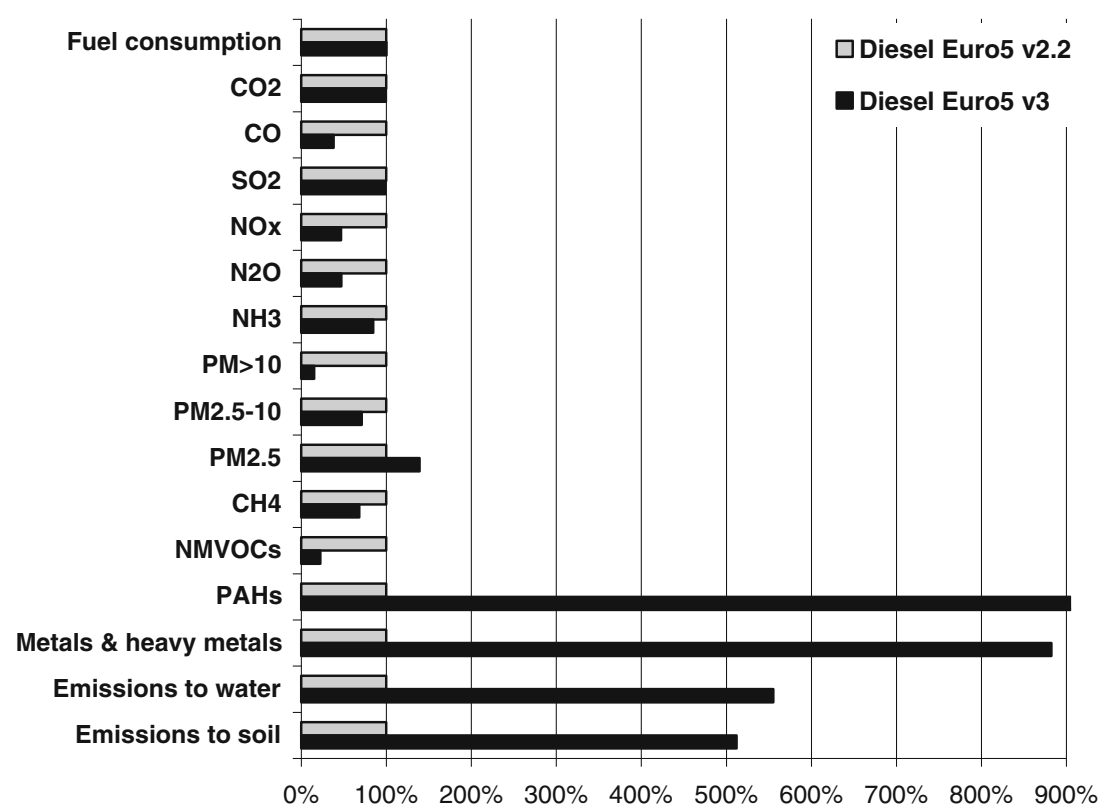

minimal adjustment from the TREMOVE model (De Ceuster et al. 2007) which provides an average data according to the very general vehicle size classes adopted here. It can therefore be concluded that the relative differences in increase in FC between petrol (and natural gas) and diesel are due to underlying differences in the actual average vehicle sizes contributing to each vehicle size class, i.e. diesel cars $>21$ seem to be heavier than petrol $>21$.

Comparison of the group 2 emission factors for petrol, diesel and natural gas fuelled vehicles is given in Figs. 4, 5 and 6. HC and VOC are here considered to refer to the same substances whilst PM exhaust emissions are accounted for as $\mathrm{PM}_{2.5}$.

Other than showing the contrast between the emission factors derived in the inventories and the actual regulated emission limits, the graphs highlight that for petrol cars there are no PM limits stipulated and that for diesel cars the limits for $\mathrm{CO}$ and VOCs (HC) are lower than for petrol cars. Whilst the limits for $\mathrm{CO}$ emissions from diesel are higher than for $\mathrm{NO}_{x}$, the actual emissions are lower. Regulated emissions for CNG use the Euro standards for petrol emissions because both use a spark ignition engine (as opposed to compression ignition). Due to the
Fig. 10 Comparison of natural gas vehicle operation inventory data. The operation dataset in ecoinvent v2.2 is not described as relating to a specific Euro class. Here, we compare the v2.2 data with the new data for a Euro 3 equivalent technology

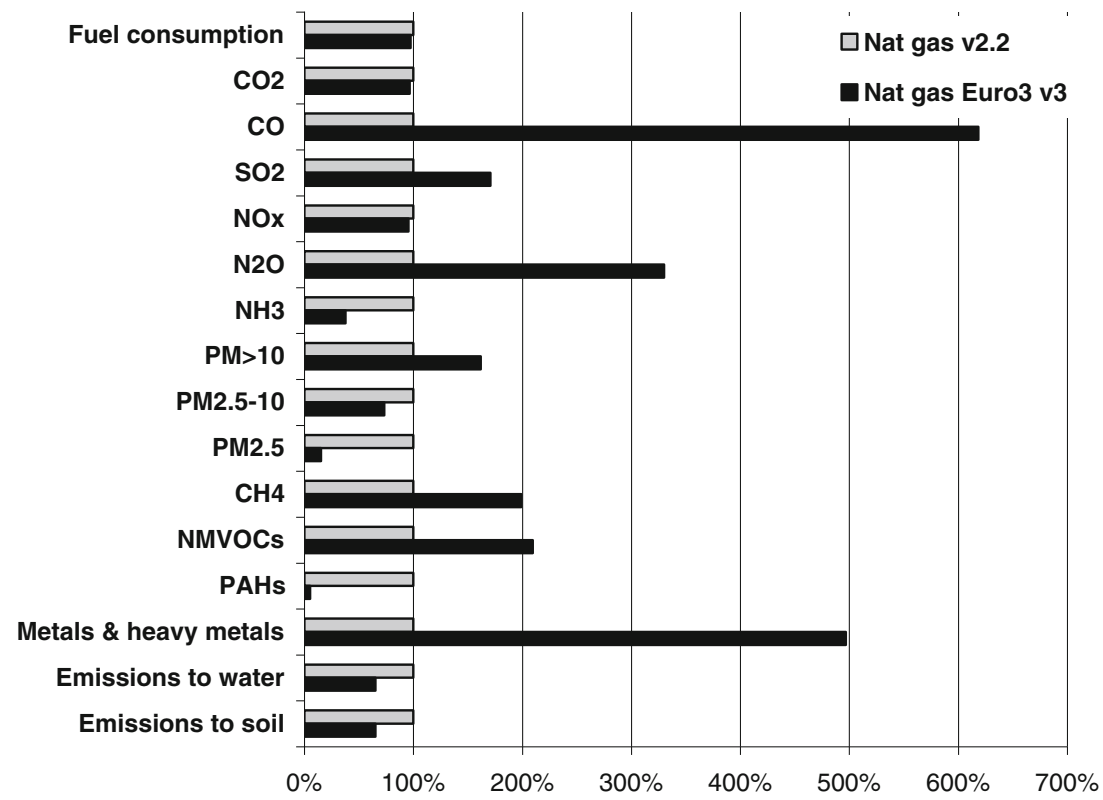


relatively very low number of vehicles determined in the TREMOVE model the data is however partly inconsistent and unacceptable. Data from Alvarez and Weilenmann (2010) were therefore used in order to form appropriate emission factors.

The FC and exhaust emissions for the medium size vehicles are shown in Table 4. Particularly for natural gas fuelled vehicles, the table shows several blank spaces indicating that either the substance is not present, is only present in very small or unquantified amounts, or that information was not available on its share. The latter is especially relevant for the specific NMVOC's from natural gas combustion. The non-exhaust emissions from tyre, brake and road wear are shown in Fig. 7 according to particulate size for each size of vehicle.

Table 5 then gives the non-exhaust emission factors relevant to $\mathrm{kg}$ tyre, brake or road emissions as well as the abrasion values per kilogram vehicle and $\mathrm{km}$. Brake wear emissions can be seen to be almost all less than $10 \mu \mathrm{m}$ in size, whilst tyre and road abrasion release also significant amounts of PM above $10 \mu \mathrm{m}$. The similarity in amounts of tyre and road wear PM can be explained by the lower density of tyre rubber in comparison to road surface material. Therefore, if Fig. 6 was shown in terms of volume of material released, then tyre wear would be significantly higher than road surface wear. Brakes are not used constantly and so have the lowest rate of wear.

In Table 5, non-exhaust emissions to soil and water, i.e. directly received by the ground and water flows, are also determined for tyre wear. Here these are in addition to airborne PM. Emissions to these mediums can be seen to account for the majority of total tyre wear emissions.

\subsection{Comparison with ecoinvent v2}

The following analysis shows the differences in individual FC and emission factors between the old and new datasets. These are reflected in Figs. 8, 9 and 10 by normalising each v2.2 factor to $100 \%$ and then determining the $v 3$ factors in terms of a percentage deviation away from them. The comparison is given for medium size cars, for petrol and diesel this uses Euro 5 and for natural gas the Euro 3 as this is assumed to be the technology representative for the v2.2 dataset.

For many of the differences, it is difficult to give specific reasons for the differences other than that they reflect alterations in the underlying data or attempts to make the emission factors consistent across vehicle sizes and emission standards (or previously undiscovered errors in the v2.2 datasets). Significant increases in the amount of metals and heavy metals as airborne emissions as well as various emissions to water and soil are indicated due to the new inclusion of a large number of additional substances previously unaccounted for within the ecoinvent database. Although these substances originate from tyre and brake wear, the increase is not reflected in PM emissions due to previous calculation inconsistencies in the totals of solid substances emitted to air.

Some similar changes can be seen for both petrol and diesel emission factors, most significantly in reductions for $\mathrm{CO}, \mathrm{NO}_{x}$ and NMVOC's - all emission factors which are taken from the more recent TREMOVE model version (De Ceuster et al. 2007). All PM emissions show a similar re-structuring whilst PAH's, metals and emissions to water and soil show similarly significant increases. Changes in PAH emissions are due to the data being taken directly from a more recent version of the EMEP/EEA guidebook (Ntziachristos et al. 2009).

As explained above, the differences in individual emission factors for natural gas vehicle operation cannot be compared to those of petrol and diesel due to the very different methodologies applied in versions 2 and 3 of ecoinvent, where the new datasets aim to use as much as possible the same data sources. FC (and therefore also $\mathrm{CO}_{2}$ ) and $\mathrm{NO}_{x}$ are seen to remain very similar but many of the other emission factors alter substantially. Although many more substances are accounted for in the new datasets, the total emissions of solids to water and soil are lower than previously accounted for even though the quantity of metals increases significantly.

\section{Conclusions}

The fossil fuel ICE passenger car transport datasets within the ecoinvent database have been updated, expanded and their structure altered for v3 of the database. Consistency across vehicle sizes and between the Euro standards was an important aspect and this has been achieved in the datasets presented. Certain errors have been corrected and the emission factors now cover a much more comprehensive range of substances. The datasets include a range of parameters which make it possible to customize the transport service according to the number of passengers and fuel consumption and these then affect important demand and emission factors. Comprehensive and methodologically consistent datasets representative of these vehicles are of increasing importance as significant academic research is done to assess whether alternative technologies and fuels truly have the potential to be more efficient and clean alternatives. The paper describes the methodology and structure behind the operation data and transport datasets as well as presenting the final fuel consumption and emission factors. The paper displays the changes at the inventory level without proceeding to the impact assessment level. Due to the extensive changes to the functionality of the database as well as to the transport datasets, impact assessment results would reflect changes in both aspects and therefore be difficult to allocate to specific changes in the transport datasets and emission factors. 
Acknowledgments The authors are grateful to Swisselectric Research, the Competence Centre for Energy and Mobility and the Erdölvereinigung for their funding of the Technology Centred Electric Mobility Assessment (Thelma) project http://www.thelma-emobility.net. For inclusion in ecoinvent $\mathrm{v} 3$, it was compulsory that the datasets undergo a critical review for which we thank Domink Saner of the etH Zurich for his commitment and time taken in this.

\section{References}

Alvarez R, Weilenmann M (2010) Tracing of Road Traffic Emissions: Natural Gas Vehicles Euro-4 and Euro-5 Standard Program. Berne, Swiss Federal Laboratories for Materials Science and Technology (EMPA) on behalf of the Swiss Federal Office for the Environment

De Ceuster G, van Herbruggen B, Ivanova O, Carlier K, Martino A, Fiorello D (2007) TREMOVE: Final Report. Model code v2.7b (2009). Brussels, Transport \& Mobility Leuven on behalf of the European Commission

Del Duce A, Gauch M, Althaus HJ (2013) Electric passenger car transport and passenger car datasets in ecoinvent version 3. Int $\mathrm{J}$ Life Cycle Assess (in press)

Faist Emmenegger M, Heck T, Jungbluth N, Tuchschmid M (2007) Erdgas. In: Dones R et al. (eds) Sachbilanzen von Energiesystemen: Grundlagen für den ökologischen Vergleich von Energiesystemen und den Einbezug von Energiesystemen in Ökobilanzen für die Schweiz. Final report ecoinvent No. 6-V. Villigen \& Dübendorf, $\mathrm{CH}$, Paul Scherrer Institut, Swiss Centre for Life Cycle Inventories

Hawkins TR, Gausen OM, Strømman AH (2012) Environmental impacts of hybrid and electric vehicles - a review. Int J Life Cycle Assess 17(8):997-1014

Heck T et al (2007) Wärme-Kraft-Kopplung. In: Dones R (ed) Sachbilanzen von Energiesystemen: Grundlagen für den ökologischen Vergleich von Energiesystemen und den Einbezug von Energiesystemen in Ökobilanzen für Die Schweiz. Final report ecoinvent No. 6-XIV. CH, Paul Scherrer Institut Villigen, Swiss Centre for Life Cycle Inventories, Dübendorf

Huo H, Wu Y, Wang M (2009) Total versus urban: well-to-wheels assessment of criteria pollutant emissions from various vehicle/fuel systems. Atmos Environ 43:1796-1804
Hussain MM, Dincer I, Li X (2007) A preliminary life cycle assessment of PEM fuel cell powered automobiles. Appl Therm Eng 27(13):2294-2299

Keller M, de Haan P, Knörr W, Hausberger S, Steven H (2004) Handbuch Emissionsfaktoren des Strassenverkehrs 2.1: Dokumentation. Bern, Heidelberg, Graz, Essen, INFRAS

Mellios G, Ntziachristos L, Samaras Z, White L, Martini G, Rose K (2009) EMEP/EEA emission inventory guidebook 2009: Gasoline evaporation from vehicles. European Environment Agency, Copenhagen

Nijboer M (2010) The contribution of natural gas vehicles to sustainable transport. International Energy Agency, Paris

Notter DA, Gauch M, Widmer R, Wäger P, Stamp A, Zah R, Althaus H-J (2010) Contribution of Li-ion batteries to the environmental impact of electric vehicles. Environ Sci Technol 44(17):6550-6556

Ntziachristos L, Samaras Z, Kouridis C, Hassel D, McCrae I, Hickman J, Zierock K-H, Keller M, Andre M, Gorissen N, Boulter P, Joumard R, Rijkeboer R, Geivanidis S, Hausberger S (2009) EMEP/EEA air pollutant emissions inventory guidebook 2009: exhaust emissions from road transport. European Environment Agency, Copenhagen

Ntziachristos L, Boulter P (2009) EMEP/EEA air pollutant emissions inventory guidebook 2009: road vehicle tyre and brake wear; road surface wear. European Environment Agency, Copenhagen

Querini F, Béziat JC, Morel S, Boch V, Rousseaux P (2011) Life cycle assessment of automotive fuels: critical analysis and recommendations on the emissions inventory in the tank to wheels stage. Int J Life Cycle Assess 16:454-464

Samaras C, Meisterling K (2008) Life cycle assessment of greenhouse gas emissions from plug-in hybrid vehicles: implications for policy. Environ Sci Technol 42(9):3170-3176

Schafer A, Heywood J, Weiss M (2006) Future fuel cell and internal combustion engine automobile technologies: a 25-year life cycle and fleet impact assessment. Energy 31(12):2064-2087

Spielmann M, Bauer C, Dones R, Tuchschmid M (2007) Transport services. Ecoinvent report No. 14. Swiss Centre for Life Cycle Inventories, Duebendorf, Switzerland

Van Mierlo J, Maggetto G, Lataire P (2006) Which energy source for road transport in the future? A comparison of battery, hybrid and fuel cell vehicles. Energ Convers Manage 47:2748-2760

Weidema BP, Bauer C, Hischier R, Mutel C, Nemecek T, Reinhard J, Vadenbo CO, Wernet G (2012) Overview and methodology. Data quality guideline for the ecoinvent database version 3. Ecoinvent Report 1(v3). The ecoinvent Centre, St. Gallen, Switzerland 